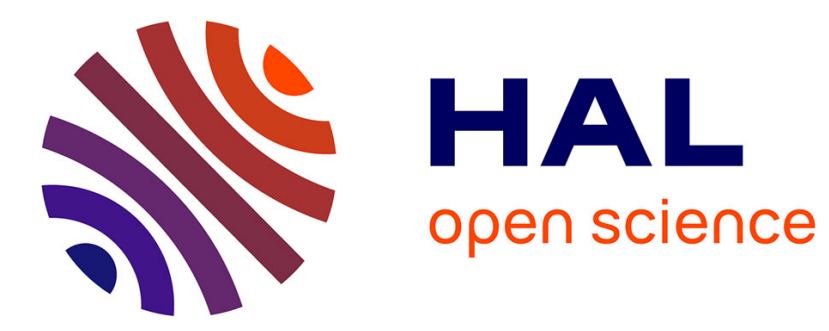

\title{
Collective memory and ethnic identities in the Colombian Pacific
}

Odile Hoffmann

\section{To cite this version:}

Odile Hoffmann. Collective memory and ethnic identities in the Colombian Pacific. Journal of Latin American Anthropology, 2002, 7 (2), pp.118-139. halshs-00463260

\section{HAL Id: halshs-00463260 \\ https://shs.hal.science/halshs-00463260}

Submitted on 11 Mar 2010

HAL is a multi-disciplinary open access archive for the deposit and dissemination of scientific research documents, whether they are published or not. The documents may come from teaching and research institutions in France or abroad, or from public or private research centers.
L'archive ouverte pluridisciplinaire HAL, est destinée au dépôt et à la diffusion de documents scientifiques de niveau recherche, publiés ou non, émanant des établissements d'enseignement et de recherche français ou étrangers, des laboratoires publics ou privés. 
Publié :

HOFFMANN, O. (2002) "Collective memory and ethnic identities in the Colombian Pacific », Journal of Lic American Anthropology 7 (2), p118-139.

\section{Collective memory and ethnic identities in the Colombian Pacific Odile Hoffman1}

In the Pacific region of Colombia the new conditions for acceding to land and to territory are arousing a strong drive to redefine identities. Blacks who had never perceived or "categorized" themselves as such in their own milieux, unless as "free agents" or in reference to names of places or rivers in areas where they had lived, without land rights, for more than a century "became" so in order to ensure themselves a degree of land security, in application of a law ( $\mathrm{N}^{\circ} 70$ of 1993). This legislation provides for the assignment of collective land titles to "black communities inhabiting the Pacific coastal region". For similar reasons, some Whites associate themselves (become assimilated?) with the Blacks and the mixed-race people, often close to the South-American Indians, sometimes claim to be "blacks", causing incomprehension and annoyance among their neighbours and officials alike, who are white.

This strange merry-go-round of identity, triggered at the start by preoccupations concerning access and control over territories, is leading to a shift in the balance of power, on the symbolic front (and soon in the sphere) as much within the groups directly concerned as on their fringes. Consequently, analysis of this trend is contributing to clarification of the processes by which barriers and frontiers are being built between groups [Barth, 1995], by defining by whom, to what end, and especially how these are being used and by emphasizing what social, historical and political contexts -at local, national and international level and at their interface- favour or induce their construction.

The approach adopted is deliberately descriptive. It starts from observation of "situations" in which these adopted identity descriptions are negotiated, by distinguishing those taking shape at the heart of black "communities" from those which are beginning to emerge at their borders (to simplify: Indians, mixed-race and Whites). In each case the study seeks to identify the conditions in which new discourses are formulated and expressed (the arenas and the tools), the individual or collective actors who contribute to this and possibly the new practices that these shifts of position involve. The accurate contextualization of these three components (tools, actors, practices) by situating them 
against their background) can yield a picture of the complexity of identity-related phenomena, while avoiding the false dichotomies of the type which sets essentialism versus instrumentalization, and to plot the local-global connections and manifold criss-crossings between the political, cultural and social domains.

In all the cases investigated, a "collective memory2" has been assumed in order to legitimize the current positions by founding them on a shared experience -real, reconstructed or mythical-, using diverse forms of communicated record -written and oral, individual and collective. Among such records, some are seemingly traditional (like the "oral tradition"), others stem from more recent usage (the "scholarly" tradition, the "community councils"), and their interaction is, in itself, a powerful creative force in cultural, social and political terms. The reconstructed collective memory therefore becomes at once the resort and the resource, end and means for elaborations of identity and sometimes throws different, even conflicting, versions into competition, depending on the actors and authors contributing to such elaborations. It could be recalled here that the incorporation of past events is always only a reformulation of events or accounts, in which selection (through omission or forgetting) and invention depend both on the actors (those for whom the account is intended), the needs of the moment and of the author (whether individual or group as a collective entity) of the reformulation (see Ricoeur, 2000).

In the Pacific region the black population, which is in the majority, has for long lived on the fringes of Colombian society, politically as well as geographically. Since slavery was abolished (18511852), migration by recently emancipated Blacks and by free workers or those already liberated for several generations intensified towards the extremely humid forests on the Pacific coast, sparsely populated and devoid of main arteries, where they settled along the rivers (see map 1). There they practised farming, hunting, fishing and gold panning. They had frequent, albeit distant, dealings with Indian groups -Embera and Waunana in the North and the Centre, Awa in the South- and, intermittently, with white traders who bought products gleaned form the forest (rubber, mangrove bark for tanning agents, corozo palm nuts) and, from the 1950s, timber (see West, 1957). The slavery phase of these people's rather particular history has disappeared from the spoken memory. This collective amnesia which wants to erase traces of suffering and humiliation, this forgetting, 3 necessary for post-slavery reconstitution of society [Losonczy, 1996] also acts as an unspoken truth, collectively assumed, a cement between new residents of otherwise diverse provenance (from the haciendas of the Andean valleys, mines in the foothills, plantations, from large luxurious houses and city residences, or still more distant, uncertain origins), who have had just as varied 
experiences and whose "common" history began only from the XVIIIth or XIXth centuries, with the migrations towards the Pacific.

Beyond this basic unity, settlement has generated an archipelago of villages scattered along the rivers, autonomous and governed by kinship. There, where memory is built on exclusively locally and contextually-derived references, as a function of relations forged with neighbouring populations and the resources and territories available: "The local hold over territory becomes ontological and shared with the others" [Losonzcy, 1996: 170, author's italics]. In these conditions, "the "black" memory appears [to be] declined in the plural: a multitude of temporalities [OH: and spatialities] juxtaposed, articulated in diverse cultural matrices" [idem: 171]. The same author talks of a "regime of scattered, discontinuous memory", associated with "melting-pot identities with open shifting borders" [idem: 165].

How, with as starting point such a fluid and mobile memory, scattered into a myriad of juxtaposed space/time elements, can be constructed any unified whole nevertheless made necessary by a changed political and social landscape? The law defines the population which is to benefit from certain rights in terms of particular geographical situations (inhabitants of the Pacific coastal areas) and race (black populations), while taking care to define "the black community" as "the families of Afro-Colombian descent, who possess a culture which distinguishes them from other ethic groups taken as a whole" (law 70 of 1993, clause 2, paragraph 5). Here, memory and ethnicity are clearly associated, making the law's application conditional on a fact of belonging to this black community whose status has been officially set into the statutes.

However, if the category "black community" is a new arrival to the general dialogue (see the attached article by Restrepo), one cannot deny the portent of an experience shared, in a general way, by people in that population and which cannot be shared with individuals who are not black. This so-called "shared" experience, most often lying unspoken (true of slavery, as already mentioned, but also of the daily confrontation with racial discrimination and exclusion), forges a feeling of belonging to a collective social entity, not clearly delimited, with no particular name, yet built in distinction from other such entities which are themselves identifiable. These are principally the Whites, the possessors, those who dominate, the inhabitants of the Andes, the Indians, and so on. Rappaport [1998: 21], working with the Indian communities of Cauca in Colombia, mentions a similar process. He draws attention to the fact that "our narcissicistic fixation about the fluidity of ethnic boundaries, despite the elegance of theories of certain intellectuals like Bhabha, makes us 
forget the palpable sensation of an "internal We" lived by subordinate groups". This "internal We" is perceived in the "memory gaps" that A.-M. Losonzcy mentions [1996], which are the shared "silences" -about slavery and day-to-day racism- rather than elements forgotten in the real sense. In other words, they are contributory parts of the collective memory and not subtractions from it. 4

Here, empirical data will be used to analyse the many different ways of formulating identity -and of managing the memory-, around a single "ethnic" group ("construction" of the concept of "black ethnic group" is not in itself a straightforward process) and in the same dimension in space and time, at least at a certain scale, that of the Pacific region of southern Colombia in the 1990s.5

Memory retrieval and black ethnic identity

Transition from the oral to the written record, the role of intellectual culture

The black population of the Pacific, long ignored by academic, economic and political spheres, has nevertheless, since the 1940s, been the subject of scientific studies which have created strong images built around some key concepts: scattered rural communities, ability to adapt to ecologically and socio-economically unfavourable environments, social organization founded on kinship, traditional production activities [see Friedemann, 1985; Whitten, 1969; Restrepo, 1997], specific cultural characteristics (dance, music, acted storytelling, certain rituals). This discourse, clearly far from being false but fixed in a notion of what rural life is like and influenced by Indian models, has considerably influenced the planning and drafting of constitutional and legislative texts appertaining to black communities [see Hoffmann, 1998a; Wade, 1996].

The intellectual realm (mainly anthropologists, but also priests, lawmakers, politicians (black and white taken together), NGO assessors) have for more than 50 years been producing a whole set of limited representations of identity. These are held up as "scientific descriptions" and begin with the principle of a fundamental state of "otherness" of the Blacks, setting great store by emphasizing their peculiarities: in their housing, their matrimonial practices, in their relationships regarding kinship, in their productive practices, their access to land and territory, and so on. In so doing, they tend to set social and cultural practices within a rigid exoticism where their flexibility is effaced in the interests of a coherent intellectual construction, largely inspired from models of social organization already known (mainly those of the Indians). The apparent "success" of these representations, disfigured as they are from the point of view of modern trends, derives, largely 
from the fact that they operate as the first written memory of these societies hitherto embedded in the oral records of communication and memory. This written, "intellectual" memory rapidly becomes a "truth" that cannot be avoided, in the absence of any real counter-proposal that might have come from other initiators or other fields.

This situation began to change in the 1980s, with the organization of some sectors of the black population and the fact that they started to speak out, first in the regional or local arenas (especially in the northern part of the Pacific region, the Choco), then, since the debate on the constitution and the drafting of law 70 (1991-1993), on the national scene (see Arocha, 1992, Restrepo and Pardo, in this collection). Within the framework of this political arousal, but also beyond, a discourse proper to these communities saw light of day. This is expressed in various forms: such as politicization, neo-Africanization, strong expression of ethhnic character (hyperethnicization), or biodiversity [Losonzcy, 1996]. These new affirmations began to take on other themes, often less ethnographic and more closely involved in national political debates than previous arguments. One of the clearly expressed objectives of the new "masters of the truth" [Détienne, 1967] is precisely that of regaining the right of expression, which they considered too often to have been confiscated by white intellectuals by which means they can erect a collective memory, essential, if the "black communities" are to be given a visible place that could be openly referred to at the centre of the complex national society.

This reappropriation of the memory, a condition for identity and recognition, becomes a large factor in struggles against domination and discrimination. For many black Colombian intellectuals, the retrieval of the memory and its transcription into written form is an explicit strategy for power, in a political context which, for the first time in Colombian history, provides black populations and their representatives with room for dialogue and recognition [see Agudelo, 1999 and in this collection].

However, a transition from the oral to the written register involves also a change in the social hierarchies regarding the bearers of the memory and the expression. For the intellectuals who have embarked on this adventure, this changeover6 implies a dual challenge. First, the winning over of the non-black intellectuals (academics, politicians, and so on) in order to confirm their place and assert the legitimacy of their producing their own discourse; and secondly presentation directly to the black populations to test the "veracity" of the positions they adopt and to spread the new word. 
Construction of the collective memory, the day-to-day discussions

In the context of the current mobilization, the debate hinges on two main notions -identity and territory. The legislative texts present the link between these as "ontological" and it sets the conditions for the very recognition of land rights. However, that association is not obvious in the case of societies until recently fragmented into an infinite number of concrete but discontinuous "territories", located along rivers parallel to one another and perpendicular to the coast. Are there as many black identities as there are local territories? Or does just one "ethnic territory" exist which is common to all the black populations of the coastal areas? These questions make it imperative to rethink each one of these terms and define clearly their interrelationships, in order to construct an accurate discourse specifically for the "black communities" now established under official statutes. This discourse would be manifestly distinct from the Indian models and take into account the concrete ways of life of the black people residing along the riverbanks (such as settlement patterns, arrangement of space, social organization). It must not be forgotten that this is a question of claiming and gaining access to rights which, in order to be taken up fully, imply the participation of grassroots populations in implementing new rules to govern negotiation and local exercise of authority. The search for a new discourse is therefore not only an intellectual speculation but belongs to the realm of the concrete. It develops in day-to-day life and demands a consensus between the different parties who, while agreeing on claiming identities and territories, nevertheless have priorities and aims which are often quite distant. Some emphasize their needs for the short or even immediate term (access to land and protection of the territories). Others hold a wide-ranging theoretical and political ambition (redefinition of the black identity).

In practice, when meetings and assemblies are organized in the villages to broadcast the details of the legislation and set up the mechanisms to implement it, those involved do achieve a compromise. These meetings are often well attended, with between 50 and 200 people present for two days in a hamlet or small village. Debate was lively, with the juxtaposition of a wealth of different forms of communication conveyed through different types of record. Space was always made available for storytellers and popular poets. School blackboards were used to display the explanations of assessors who came from the town, attendance lists were circulated. Discussions sometimes degenerated into internal score- settling. The day's proceedings might be rounded off with a video film and later everyone found a place to lay down his sleeping mat for the night. As Villa [1998 : 444] describes, "Singing and dancing became incorporated in the political dimension of the meeting, the older people recall the history of the settlement along the river, on the map the 
places where the forebears set up home are drawn, they tell us stories of masters and slaves, of meals and festivities of the past, of Indians and of Blacks and about the history which, in the meeting, is the bearer of identity."

These "moments" act as sites for the construction of history (that is, of the narratives accepted by consensus) and of collective memory, where poets play a decisive role. In the Pacific region, the decimeros and the copleros recount the past in verse and make fun of the audience, treat the powerful with irony and defend the weak. Here we find again the traits associated with orally-based societies, in which the collective memory is passed on by way of processes of "generative reconstruction" (and not in the form of a mechanical memory delivered word-for-word) where the narrative aspect is fundamental and grants the memory a high level of creativity [Le Goff, 1988] as well as a large capacity for manipulation (compare the cases of imposed memory or of those espoused by obligation, discussed by Ricoeur, 2000).

These processes enable rural people, who are often illiterate, to participate alongside the leaders, in the retrieval of the memory. The bringing together, in the same space and time of these two symbolic registers (traditional ritual and modern political ritual [see Bierschenk, 1995]), allows each of the parties to get to know each other and to contribute, in however unequal and dissymmetrical a fashion, to an enterprise in which the objectives might be distinct but can, in a given situation, find common cause in the quest for legitimacy.

The assemblies organized for reasons of politics and territory, are often charged with emotion owing to their exceptional character as encounters of people who were in contact without knowing each other. They provide the opportunity to spread the word about new standards and the new memory, this time from the intellectuals to the rural populations. In this objective, the retrieval and revaluing of "ancestral" practices, elements given as proof of condition and identity, play a central role. That is often done by recalling the terms which designate them, often fallen into disuse and the process gives rise to some strange exchanges.

During meetings of the Rio Mira Community Council, it could be seen how certain terms were being reappropriated by regional leaders (who were mostly from the towns) then spread in turn to the rural people who thus "learned", from the mouths of some younger than they, the value of practices which were often obsolete: collective work (minga, a term of Quechan origin) for land clearing now rare, group hunting operations when there is no longer any big game, work exchange 
now replaced by paid jobs on the large plantations, and so on. Although the practices might well be obsolete, the discourse is very much one of today and establishes a reversal of authority between generations. The elders, whose wisdom and knowledge is revered, are called on to validate the argumentation of the younger people, even if it means suppressing any of their doubts or reservations. That was the case, at one of the meetings, of an old man who publicly asked the community to pardon him for having dared to contradict a young leader on "ancestral practices" about which he had doubts, thereby jeopardizing the collective memory and identity. On another occasion, it was the same leaders who in a plenary meeting used words deemed to be traditional such as porfia (a collective discussion held to find a consensus), which none of the rural people attending either use or even understand. No-one dared to ask the meaning and the only person who mentioned the question was reprimanded for his ignorance. It was even questioned if he really belonged to the community.

From the intellectuals' point of view, this effort to recycle and give new meaning to ancient terms (minga for "plenary assembly", porfia for "conference") matches a determination to affirm the particular nature of practices and vocabularies in order to assert an identity distinct from that of their neighbours (Whites and Indians). The campaign recalls the efforts of Nasa Indian intellectuals, in the Cauca area of Colombia, who endeavoured to rework "historical, ethnographical and linguistic knowledge so that they reflect the "native" Indian expectations and epistemologies rather than western ones" [Rappaport, 1998 : 31]. It aims in the end to form links between modernity and tradition, by incorporating rural populations in the vast undertaking that is the reconstruction of the memory, at the same time answering the needs of decision makers, often brought up far from the rural world, to persuade the older members of the society of the legitimacy of the new practices (mobilization and political organization) by means of their knowledge of things "traditional" (the vocabulary).

Whether in meeting requirements stemming from legal texts -which set up the traditional as the essential condition of identity- or in response to the dynamics of popular mobilization -which reconjours the worth of forgotten practices and values-, reference to ancestral life has become obligatory and indispensable in the elaboration of ethnic identity. The foundations of the collective memory, those traits deemed to be "ancestral" are brought back to the surface. They are sometimes invented, always reworked and recontextualized, before being rediffused in various forms and for a variety of publics (through writings, videos and talks). 
On the one hand, these dynamics allow circulation of knowledge, with the additon not always in a controlled- of certain elements along the way. There is also mutual feedback between spheres which hitherto hardly mixed (the intellectual culture and the oral tradition, the rural people and the assessors from the towns). On the other hand, the reliance on the written medium brings risks of crystallization and reification of the discourse around a handful of powerful ideas. Thus, the campaigns developed by the intellectuals can lead to standardization of identity through homogenization of the memory. That in turn supposes a degree of confiscation of various elements of popular memories. The intellectuals nevertheless cannot ignore the great vitality and variability of rural populations' practices and are led to make innovations by constructing day by day better defined categories more "respectful" of grassroots black communities. The notion of "territory" has been considerably enriched with numerous debates held in villages in the coastal areas, embracing elements drawn neither from nature nor even from spatial factors (the territory as space of reference, even if it is sometimes broken up and under the control of others), and the very definition of "black identity" is constantly called into question and enriched by the ways in which the rural people use it, in daily contact with their non-black neighbours.

Identity-related negotiations with "the neighbours" (Whites, Indians, mixed-race people)

If this commotion around identity leads to the definition of a "black state of being" whose construction is incumbent on "all Blacks" (the discourse of the major black organizations, including the PCN, Proceso de Comunidades Negras, Grueso Rosero and Escobar, 1998), what is the situation of those whose racial identity is not clearly defined, those who fall outside the categories currently officially recognized and those who do not think of themselves as others might classify them? These are the people of mixed race with the most diverse racial ancestries: rural whites integrated for generations in villages of black communities with whom they share the same way of life, Indians who refuse to live on reserves and coexist with Blacks while holding for them a historical -and anyway mutual mistrust. The local societies of the Pacific region, quite particular in their settlement history, as has been seen, have harboured all manner of unions and alliances, or have done the opposite by erecting insurmountable barriers between social groups made distinct by their racial inheritance. Today they have to manage these socio-racial combinations, under the manifold pressures which push towards the establishment of identities closely defined by specific characteristics and as unequivocal homogeneous entities. Three case histories will illustrate the resulting debates and the "solutions" found to date -and which could change virtually overnight, in 
that the whole issue is in the throes of the definition process. The three examples are: enclaves of White village communities on the north coast of Nariño; the mixed-race villages of the piedmont; and the black and/or Indian individuals living within the black collective territories which are being constructed.

The Whites of the north coast

There are a dozen or so "white villages" situated on the coast north of Tumaco. These are peopled, in one case, by descendents of colonizers of unknown origin who left neither traces nor "history" (San Juan) and in another by the "heirs" -the name they call themselves- of a Spaniard who bought a strip of beach at the end of the XVIIIth century and jealously kept all control -and the original land titles-, going so far as to indicate, in his will, the rights of use and division that his descendents had to respect (Playa Mulatos) (see Map 2).

The daily way of life of these villages (housing, food, fishing and farming practices, religion and even their music) is very similar to that of the black village communities of the surrounding area. This is in spite of their chronic isolation, another point in common which persists (four hours by outboard and 12 hours by canoe from Tumaco or Guapi, the two nearest towns). Until about 20 years ago no real contact was conceivable between these two groups. If a Black person ventured onto the beaches of San Juan or Mulatos "he was turned away and all traces of his presence were removed, even down to his footprints in the sand" or "they broke the glass he had drunk in",7 a stark way the Whites have to deny the very existence of the humanity of the Other, who is black. These culimochos, as they are crudely and disparagingly called in Tumaco, had built their small local-scale domination on exclusion and racial discrimination, on the affirmation and preservation of identity (white in this case, with a strictly monitored endogamy) and, in the case of the Mulatos, on the control of the territory handed down intact -as jointly held property- from generation to generation. It is from this base of "spatial capital" that they were able to ensure that they reproduced and expanded. From the beginning of the XXth century, they became distinct from the black village communities in certain activities, including some basic tourism for town dwellers of Buenaventura and a few adventurers from the interior of the country. In the 1940s more imposing buildings (so-called "hotels") appeared and a clear economic stratification was added to the existing racial segregation. 
During the years 1980-1990, this microsociety saw itself seriously threatened by a weakening of its two mainstays. Its economic strength was severely affected first by two earthquakes which were followed by tidal waves, in 1949 and, especially so, in 1979. These events destroyed facilities, caused land to disappear, many deaths and the departure of survivors who had lost everything. Secondly and more recently the society has been weakened by the loss of the legitimacy of its racist "values" which are being overturned, or in any case no longer endorsed by the overall discourse which advocates ethic and racial equality.

At San Juan, the "small white people" of the coast are confronted with a problem which, until only a short time ago, they did not share with blacks -the non-legal status of their land rights- but which the blacks are resolving in the context of law 70. From now on, it is the very basis of their survival -their territory- which could be threatened in the near future. The law makes provision to regularize the titles, in the collective form, for the benefit only of the "Afro-Colombian" populations. At the same time it forbids any regularization of land issues without the official agreement of the "black communities" neighbouring land in question. Will this be a new chapter in the universal story of the boot being on the other foot? The whites are today dependent on the blacks in their legitimate move for land security. Unless they declare themselves as "blacks" in order to benefit from the law, insofar as they fulfil all the conditions laid down by the legal texts (ancestry, traditional practices, respect for the environment, and so on) except those relating to ethno-racial traits ("phenotype").

Without going much further, it can be seen how this small society reacts to what it sees as successive "ironies of fate". One option, which indeed is the most frequent, consists in leaving the coast to settle in the town. There, individuals rebuild their projects on other foundations, far from the rural life and fishing, continuing and sometimes feeding racism in the towns and in some cases getting closely involved in politics. Those who stay in the villages on the coast change over to other productive and/or economic activities (especially, control of the timber trade) which enables them to maintain their economic superiority over their small area, away from their "ancestral" territory. Finally, a small minority seems prepared to stay in the village, even if it means making deep changes to their local ancient racist practices, as evidenced for example by a rise in "mixed" marriages and a relative fall in discrimination. They therefore have to renounce their "ancestral" discourse to construct another, which incorporates the new living situation common with that of the blacks. 
In all these cases, the hegemony of the whites in the territories they controlled is being strongly called into question. The blacks and the mixed-race blacks can live in villages of "the coast". The whites have lost a large amount of their spatial capital, which they are seeking to transform as rapidly as possible (into economic capital and political capital) before they give out completely. History will have wanted it that, locally, the economic -and natural- dynamics and development of the global political context- join forces to counter an original small-scale social formation, founded on racism and segregation, which had been able to reproduce itself during two centuries of isolation.

The mixed-race people of the piedmont

Neither Blacks, nor Whites, nor Indians, the mixed-race peoples live neither on the coast nor in the mountains. They occupy their land without the cover of legal titles. They do not aspire to go to the nearby Indian reserves but cannot lay claim individually to a legalization of their land-holding situation, in the form of private property, because the area they inhabit, in the foothills of the sierra has been declared a "fragile, inalienable protected area" by the Colombian Institute of Agrarian Reform (INCORA). In addition, they are mostly recent inhabitants, second or third generation at most, who originate either from the neighbouring Indian regions, or from the sierra or indeed from the coast. They are poorly regarded by the authorities as a group which is not socially homogeneous, with neither collective memory, recognized rights, nor shared identity.

The problem of land security can, in their view, be solved only by inclusion in a clearly-defined position in the "table of identities" provided by the legislation. So long as they remain classified as a population shifting in terms of space and identity, they cannot aspire to the political influence which would enable them to air their claims. They therefore have to become slotted into the framework elaborated from national and global criteria.

The regime of private property is beyond the reach of these people, unless they exert political pressure outside their region to justify an exception to or a reworking of the rule. These two strategies are currently impossible because the peasants have almost no negotiating power.

The regime of Indian reservations, although in some respects the most efficient and rapid means of obtaining and guaranteeing territories, 8 supposes in exchange the setting-up of and respect for the corresponding local institutions (cabildo, gobernador) and incorporation in the structure of regional 
and national organizations (ONIC, National Indian Organization of Colombia). For these scattered populations, who moreover are quite individualized in their practices, the adoption of an Indian land property regime and of the associated identity would undoubtedly be strongly restrictive.

In this context and from a pragmatic point of view, the "black" solution would still be the most feasible one. The life styles (use of land, social organization) are objectively quite close to those found among the coastal communities, with the traits of mobility and flexibility. The conditions stipulated for obtaining collective titles are less restricting than in the preceding case in that the black regional and national organizing structures are far from being consolidated, which gives room for manoeuvre to local initiatives and innovations. However, seen from another angle, the cost of this redefinition of identity is high: claiming to be Black involves taking on the stigmatization which is still associated with this category, exposing oneself even more to discrimination and racism, which are still strong in the region, as in the country as a whole. For people to "become Black" means that they must recognize themselves as a member of a collective whole, and of taking part in the efforts and campaigns to gain power that this new social actor is running or trying to conduct. Well beyond being a simply instrumental identity expedient for obtaining land rights (a kind of legal quibble), this new positioning in the social and political space demands considerable commitment at an individual and collective level. This is not apparently too daunting an obstacle. Initiatives in this direction, supported by certain sections of the Catholic church, show this. Efforts towards this include organizing meetings and primary negotiations between neighbours; the essential work on the memory which consists in retracing the history of migrations and of the first arrivals, locating ancestral houses (whether still existing or not), reconstructing family and village genealogies and mapping a theoretical future collective territory. When indeed the various Indian, White, mixed-race and black roots are so inextricably entwined, the notion of belonging to "black communities" does not appear as incongruous as it might at first glance. Recent history brings together these families who have to face the same problems of social and political recognition, on the one hand, and recognition of land rights, on the other. The "collective memory" under construction might well favour one of these aspects -black culture- without jeopardizing the identity of individuals.

Nevertheless, such a process has a long way to go. Moreover, some object to the right of these inhabitants to claim "the state of being black" for themselves, by putting forward arguments relating to their racial phenotypes: these people are not seen to be "real Blacks". The official institutions thus avoid tackling an explosive issue, by continuing to consider these populations as a 
juxtaposition of illegal settlers. For their part, the black organizations already formed have sometimes difficulty themselves in recognizing these highly diverse groups as belonging to them. They fear that the ethnic mobilization process is being exploited just in the interest of territorial aims.

Individual position taking

The mobilizations concerning identity mentioned thus far do not concern only debates on ideas or stakes involving whole groups; they suppose the existence of positions taken by individuals which develop through attendance at meetings which bring together the inhabitants to discuss the implementation of law 70 and constitution of collectively-held territories.

The territory being formulated in the Upper Mira area consists of about 30 hamlets or small villages. It is surrounded to the east by Awa Indian reserves, to the West and North by extensive palm groves, or already old-established pastures, the property of agro-industrial concerns from Cali or Bogota, and to the South by forests being steadily cleared by these same companies hungry for new land, most often without land titles or after non-legalized purchases. Caught between two neighbours strongly tempted to expand their territory, peasants of Upper Mira find it difficult to control their own area. That is made more problematic by the growing of illicit crops (coca) which have been spreading enormously for several years, bringing in new, non-black inhabitants reluctant to discuss land rights. Deliberations on how to organize people to demand recognition of their territory are thus initiated and proceed against a background of tension between different camps.

During an assembly devoted to the mapping of the boundaries, villages, various places and spaces within this territory, the open or developing conflicts with white settlers near the borders were naturally brought up. However, it was not until the end of the second day that the peasants mentioned the existence of a small locality composed of half-a-dozen houses inhabited by Whites, within the territory and recorded in by census established by the black community. For those in attendance it was obvious that those people would be incorporated into the territory, with no need even to discuss the matter in the meeting. Settled for two generations, these Whites made up an extended family who worked and lived like their black neighbours, starting to intermarry under the same conditions and take part in all aspects of local life. The racial phenotype did not at any moment appear relevant, in the view of the Blacks present at the assembly, to justify possible exclusion, or simply to cast doubt on their rights on the territory. Even the external assessors, surprised at first, adopted this position. The black/white opposition, which was historically 
determined and in turn decided relationships between the ethnic groups, is pertinent in that it conveys a relation of domination and exploitation. When this kind of relation becomes blurred locally, the opposition weakens also at this level, without necessarily losing its "efficacy" at other levels (regional or national).

Contrary to this, on the second day of the same assembly an Indian peasant arrived who hoped to take part in the meetings, seeing that he lived in a village included in the projected collective territory. A murmured discussion took place in a room next to where the newcomer was waiting, in order to decide how to deal with his case. One man (himself halfcaste) was saying that the Indian could not take part because he was not black; another responded that the Indian's wife was black. A third replied that that was not a criterion: his wife could attend if she was interested but he had no right to speak himself. Finally, after a quarter of an hour of discussion, a consensus emerged to accept him, because he had been an "active resident" for several years, integrated into the network of traditional, informal exchanges which characterize local life (associated with food, work, small acts of help to look after children, for example, acts of support from time to time) and willing to participate fully in the discussion process. Here, the "cultural difference" was brought to the forefront in order to justify the man's exclusion. This fits an argumentation which feeds simultaneously ?????(passage/ligne manquant?)the idea that it can be explained by the historical antagonisms which persist on both general and regional levels between Blacks and Indians. The conflicts over the distribution of resources coveted at a given time (territories, of course, but also, in earlier times, women, or more recently positions of political representation) can be interpreted in terms of "cultural" and "historical" opposition between two worlds and between two essentialized collective identities. Nevertheless, this bipartisan vision (Them-Us) does not stand up to local conditions which demand a more complex arrangement of relationships.

These two cases show how criteria for identity which operate in daily life, far from being restricted to racial phenotypes and to "standardized" versions of ethnic identities, are part and parcel of individuals' life in society, of their participation in time and in the territorial space (its memory) and because of that are going to differ from one place to another. In some territories, the Whites are clearly the "enemies" (in territorial terms) and no compromise is thinkable. Elsewhere, it might be the Indians who are cast as the Others who pose the threat. Finally, in other cases, the combinations are more complex and oblige people to soften their positions. Here we could take up the notion of "those nearby" dear to Ricoeur, this whole where "the push-and-pull of distancing and bringing together make proximity a dynamic relationship in constant motion" (2000:161). Neither strictly 
territorial, nor strictly ethnic, the local solidarity and common belonging will depend on conditions for effective sharing of resources and their management, the "group of near-neighbours" becomes the pertinent level of sociability, the one where the collective memory builds up, without cultural or historical determinism. This memory does not limit itself either to the territory as a concrete space which can be clearly delimited, but indeed to the social link which is associated with it, to the sharing of a day-to-day culture.

The collective memory, a construction under observation

The construction of the collective memory develops in a dialectic between more or less explicit individual interests and collective strategies to respond to certain needs. In the case of the Pacific region of Colombia, these are practical -the control of territories; political -position as political actor on ethnic bases; and even "existential" -"to feel black" and to proclaim it as a condition at the same time as a focus for mobilization: "People want to feel the pride of being black. It's a collective feeling."9 According to whether one or other of these factors is dominant, the stress is placed on the memory of the territory which nourishes the construction of a black ethic identity, or more pragmatically on a collective memory of occupation of the places and of the lands which justifies the use, the possession and finally the acquisition of landholding titles. The memory is therefore the result of involved processes, rather than a piece of information marking the starting point that must be "retrieved" in order to achieve some objective or other.

In all these cases, however, the reconstruction processes imply an effort of innovation taken on by both the leaders and the rural populations, in the content of the memory as in the ways in which it is transmitted. This is true concerning the emergence of new actors sometimes qualified as ethnic gobetweens, or "cultural brokers". These young people have received education and are often from urban areas. They find themselves at the intersection of discourses which relate to the global and local, who are capable of using the codes of either of the two worlds, and to switch from a political logic to one based rather on ethnic and social considerations depending on the contexts and the major interests at stake of the moment. They can adapt to the different levels of operation and the expectations of the people they deal with. By introducing new sources of legitimacy, their intervention can call into question local systems of hierarchy and authority (between rural and urban centres, also between peasant farmers and technically-trained people, the literate and those who have not had schooling, young and old, Blacks and Indians, and so on) and cause prejudices or 
even disputes. Although often recognized and appreciated by rural inhabitants for the abilities in conveying and spreading the new discourse, these young "intermediaries" cannot always resist the temptation to seize the memory and impose the "authorized" version of history.

In a general way, the categories devised by the "river people" concerning identity are often more subtle and more flexible than those put forward by the intellectuals and leaders of the black movement (see for example the combinations of racial-phenotypical, residential, family relationship criteria and social practices for defining who is a member of a territory and therefore "black"). More than being a contradiction, this discrepancy responds to external constraints which cannot for the moment be overcome: the leaders can only situate themselves in the national frameworks developed elsewhere (in the capital, in political circles) which demand that the particular characteristics be stressed and thus push towards an "essentialist" interpretation of the social, cultural, economic and political realities of the populations concerned. At the grassroots, in contrast, the daily experiences of coexistence would rather generate flexibility and negotiation. Here we find the distinction that many authors mention between the discourse intended fro the exterior and those elaborated inside the "communities" [frontstage/backstage of Goffmann, 1973; Feierman, 1990; public transcript/hidden transcript, of Scott, 1990]. Paradoxically, it is being seen that, under the effect of globalization, the trend is towards the imposition of "particularist" discourses and the refusal of local diversity to the benefit of more standardized versions of multiculturalism.

NOTES

1 Geographer, IRD (Institut de Recherche pour le Développement, Paris).

2 Defined here, without entering into either classical [Halbwachs, 1997 (1950)] or more contemporary [see for example Hobsbawn, Ranger, 1983] theoretical debates, as those parts of the past which remain in the present life of groups, or indeed what these groups make of the past [see Pierre Nora, 1984].

3 See M. Augé [1998 : 122] : "One must forget in order to stay present, forget in order not to die, forget to remain faithful." -

4 In this respect, the now frequent considerations about the " unspeakable " concerning the concentration camps and the Holocaust could be broadened in scope to other contexts, including that of contemporary racism [see Le Breton, Ricoeur, 2000]. 
5 The data result from work in the field carried out as part of a research programme "Identities, mobility and urbanization of Afro-Colombian populations of the South-West Pacific region, " conducted jointly between IRD (ex-ORSTOM) and the Universidad del Valle, Cali (1996-2000). In particular, the descriptions of assemblies (see further on) stem from the Author's attendance at these meetings, either as "observer" invited by the black community organizations (in the Lower Mira), or as an "assessor" in terms of the mapping part of the study prior to official institution of the collective territory status (Upper Mira). Additional material came from informal meetings and discussions with and between members and leaders of black community associations, in the Tumaco area, in 1997, 1998 and 1999.

6 I am referring here to the rural Pacific areas. In more general terms, this transition from oral to written record clearly does not date just from the past few years, neither in the towns of the Pacific where black intellectuals have been making their mark since the XIXth century (with poetry, literature and in politics), nor especially in other regions of the country, more integrated in the nascent modernity, where Blacks filled functions and had roles which brought them into the realm of written communication, already in colonial times (free workers, tradesmen). A subject of research would indeed be to find and contextualize these writings whose value has up to now been largely ignored.

7 Interview at San Juan with black inhabitants, workers who depended on the whites who live in an adjoining neighbourhood of the same village, October 1997.

8 Since the Indian movements revived in the 1970s and especially since the 1991 constitution was adopted, the Indians have acquired such a strong negotiating power that, at national level, they have been able to extend the system of reserve territories. They now control nearly a quarter of the national territory [see Gros, 1996].

9 " El derecho a ser negro es tambièn un sentimiento, la gente quiere sentir pleno orgullo de ser negra. Hay un sentimiento colectivo. (...) En los rios se decia que un criterio a tener en cuenta para que alguien los represente es que sea y se sienta negro " [" Movimiento negro, identidad y territorio. Entrevista con la Organizaciòn Negras de Buenaventura ", p.246]. 